\title{
Change within Permanence: Time and the Bivalent Logic of Economic Analysis
}

\author{
Richard E. Wagner \\ Department of Economics, 3G4 \\ George Mason University \\ Fairfax, VA 22030 \\ Phone: 703-993-1132 \\ Fax: 703-993-1133 \\ Email: rwagner@gmu.edu
}

\begin{abstract}
The logic of economic inquiry requires two distinct research programs. One program treats economic life in terms of invariant formal categories across time and place. The other program treats the continual of novelty and turbulence through time through human interaction. These programs are not commensurable: one can't be reduced to the other. The former program must be conveyed by a theory of equilibrium; the latter program requires a processbased theory of emergent phenomena. Where Roy Weintraub articulated a neoWalrasian research program in his General Equilibrium Analysis, here I sketch a complementary neo-Mengerian program. In presenting this sketch, I also explain that needless analytical confusion and antagonism can result from a failure to recognize that economic analysis requires two distinct research programs. As a historical side-bar, Carl Menger probably recognized this situation, as evidenced by his correspondence with Léon Walras.
\end{abstract}

Keywords: Carl Menger, Léon Walras, emergence, scientific research programs, social ontology, time and economics

JEL Codes: B1, B4, B5, D8, E1 


\section{Change within Permanence: Time and the Bivalent Logic of Economic Analysis ${ }^{1}$}

This paper seeks to explain why the logic of economic inquiry requires two distinct and non-commensurable types of research program. One type explores eternal phenomena; the other type explores temporal phenomena. The former type of program explores those phenomena that are independent of time and place. What arises out of this program is an understanding of invariant patterns of social reality, eternal verities if you will. The other type of program explores the generation of the particular patterns that constitute social reality in particular times and places. This latter program seeks to explore how the universal qualities of economic order are transformed in their particular features through time. The continual operation of these processes of internally-generated transformation must be conveyed by a process-based theory of emergent phenomena. The former program stands with Ecclesiastes in affirming that there is nothing new under the sun; the latter program stands with Heraclites in asserting that it is not even possible to step twice into the same river.

A distinct research program can be developed around each orientation and with both programs being valid explorations of their domains of inquiry. These alternative programs, however, are not competitive with one another; rather they are non-commensurable. The two programs do not represent contestation over the same territory but cover distinct but tangential aspects of social life, much as illustrated by the two parabolas $X^{2}$ and $-X^{2}$, sharing a common origin but pointing in opposite directions. I shall designate these 
research programs as neo-Walrasian and neo-Mengerian because the terms are in common use and map into the common distinction between neo-classical and Austrian economics, though I am not fully comfortable with this nomenclature for reasons that will be noted below.

Roy Weintraub (1993) articulates a neo-Walrasian research program, noting that this program was not created by Léon Walras but rather emerged through scholarly interaction among economists, many of them Austrian, who sought to pursue the program of general interdependence that Walras (1874) sketched. The neo-Walrasian program seeks to advance claims that are valid independently of any particularities of time and place. We can all recognize the truth that there is nothing new under the sun. But we can also recognize the truth of the claim that we can't even step twice into the same river. The alternative, neo-Mengerian research program seeks to articulate how the temporal experience of life varies with time and place through interaction among economizing people. Among other things, much needless analytical confusion and antagonism has resulted from the failure to recognize that logic of economic theory requires two distinct but non-commensurable research programs. As a historical side-bar, it is worth noting that Carl Menger (1871)(1883) probably recognized this bivalent setting for economic theory, as evidenced by his correspondence with Walras. When Walras asserted to Menger that both shared a common interest in changing the direction of economic scholarship, Menger responded that: "There is indeed a resemblance between us. There is an analogy of concepts on certain points but not on the deeper questions." 
I start by sketching the neo-Walrasian and neo-Mengerian research programs to illustrate their complementary but non-commensurable character. Next, I explore how needless controversy can arise when phenomena suitable to one program are examined within the other program, for a focus on the dynamics of temporal processes cannot be merged with a focus on the statics of eternal verities. In other words, epistemological concerns must be addressed in the aftermath of appropriate ontological identification. The remainder of the paper provides two illustrations of the different orientations provided by the two research programs, one micro in character and the other macro, showing in the process both the complementary and the non-commensurable character of the two programs.

\section{Alternative Research Programs for Economic Theory}

A focus on eternal validity independent of time and place generates a distinct research program from a focus on the emergence of particular societal configurations at particular times and places. I describe these alternative research programs as neo-Walrasian and neo-Mengerian. To be sure, the dichotomy I have in mind extends beyond those Léon Walras (1874) and Carl Menger (1871)(1883) and the traditions they represent. For instance, the neoMengerian program was present in the theories of spontaneous order we associate with the Scottish Enlightenment (Daiches, Jones, and Jones 1986). Similarly, the neo-Walrasian program was present in much preceding theologically-oriented scholarship that sought to articulate the order of creation 
(Viner 1972). Where the scholars of the Scottish Enlightenment and Carl Menger sought to theorize about on-going processes of development, the natural law theoreticians and Léon Walras sought to articulate the eternal logic of relationships outside of time. ${ }^{3}$

The distinction between the neo-Walrasian and the neo-Mengerian research programs should not be assimilated directly and immediately to some dichotomy between neoclassical and Austrian economics which is often given play (compare, for instance Rosen (1997) and Yeager (1997)). The intellectual genealogy is more complex than that. The philosophers of the Scottish enlightenment could hardly be called Austrians; moreover, a good deal of Austrian-inspired scholarship after Menger largely embraced the Walrasian orientation, as Gloria-Palermo (1999) explains. Both the neo-Walrasian and the neo-Mengerian programs are reasonable objects of scholarly inquiry, but they are different, non-commensurable programs. While they share a common origin in generalized interdependence among economic phenomena, they point in opposing analytical directions: one toward phenomena that are independent of time and the other toward the generation of phenomena that emerge through time and so vary across place.

The neo-Walrasian Program. The neo-Walrasian research program construes an economy as an equilibrated system of fully connected markets that can be separated into product markets where goods and services are exchanged and factor markets where inputs are obtained and incomes earned. A disturbance in the market for one product will also affect the market for other 
products, as well as the market for inputs used in the production of products.

This framework provides a sharp sketch of the interrelated character of economic activity within a society; it shows crisply how changes at one point in the nexus of economic relationships will induce changes elsewhere in that nexus.

During his thorough examination of what has emerged as the neoWalrasian research program, Roy Weintraub (1993) summarizes the hard core of that program in terms of six presumptions that themselves are not open to empirical examination, but which provide the grammatical or metaphysical framework for constructing theories. Table 1 presents Weintraub's list; momentarily, I will present a similar list for what I perceive to be a neo-Mengerian research program. To be sure, there is surely some scope for the development of other lists of the neo-Walrasian hard core because there is no formal convention that ratifies or adjudicates this list. The list is rather an articulation of what seem to be the bedrock presumptions held in common by a large body of economists who produce scholarly works within a neo-Walrasian motif. The central point, in any case, is that any scholarly work will have some such accepted hard core that provides the point of departure for that work; any system of thought must contain exogenous variables.

\section{Table 1: Hard Core of neo-Walrasian Research Program}

1 There exist economic agents.

2 Agents have preferences over outcomes.

3 Agents independently optimize subject to constraints. 
4 Choices are made in interrelated markets.

5 Agents have full relevant knowledge.

6 Observable outcomes are coordinated, so they must be discussed with reference to equilibrium states.

Source: Weintraub (1993), p. 109.

Scientific research programs also operate with both positive and negative heuristics. The positive heuristics provide guidance for the construction of theories; those heuristics promote the construction of theories that are consistent with the metaphysical hard core of the research program. In his presentation of the neo-Walrasian program, Weintraub (1993) presents two positive heuristics: (1) theories should contain agents who optimize and (2) theories should make predictions about changes in equilibrium states in response to specified exogenous changes in parameters. A similar articulation of a positive heuristic was articulated by Reder (1982), who argued that economic models should be based on two presumptions: (1) agents maximize and (2) markets clear.

The methodology of scientific research program also includes negative heuristics about what to avoid in the construction of theories. The real work, though, is done through the positive heuristics, for it is in light of the positive heuristics that the scholarly work of constructing economic theories is accomplished. In contrast, the negative heuristics just tell someone what not to do and what to dispute about someone else's work. Negative heuristics counsel researchers on how to avoid entering what the hard core would reveal as 
intellectual swamps. Weintraub (1993) lists three such negative heuristics for the neo-Walrasian program: (1) don't allow irrational behavior, (2) don't work without a meaningful equilibrium, and (3) don't think about testing empirically the hard core propositions.

The neo-Walrasian program seeks to characterize an orderly economy in terms of consistency among various postulated relationships regarding such things as consumer demands and producer technologies. What consumers will demand depends on their incomes; those incomes depend on the prices paid for productive inputs; the value of productive inputs to producers depends on the desires of consumers to buy those products. What results is a circular system of reasoning that reflects its logical consistency but which cannot be used to generate those relationships in the first place. This system stands outside of time and is incapable of being relocated inside of time because its conceptual categories are incapable of being used to generate the observations to which those categories pertain; the analytical forcus is on what Böhm (1992) describes as logical causality, in contrast to generative causality.

The neo-Mengerian Program. In contrast to Walras, Menger's analytical vision suggested a generative or emergent orientation toward economic phenomena, wherein complex macro formations emerge out of interaction among simpler micro units. ${ }^{4}$ Menger was an incipient theorist of emergent complexity for whom the move from the individual or micro level to the societal or macro level was an elevation in analytical level, with macro phenomena emerging out of interaction among micro units. In this respect the neo- 
Mengerian program is the antithesis of the neo-Walrasian program. Menger wrote long before such techniques as agent-based computational modeling had arisen, but it's clear that Menger's theoretical intuitions would have supported emergent and generative styles of theorizing, much as Vriend (2002) claims for Friedrich Hayek. This reduction of societal phenomena to objects of individual choice is antithetical to the Mengerian vision. When many Crusoes interact, patterns emerge that would never have occurred through isolated individual action. Property, contract, legislatures, legal proceedings, and money are all phenomena of interaction and not of choice. Institutional arrangements are a macro and not a micro level phenomenon. These phenomena represent a new level of existence that arises through interaction at a lower level. Accordingly, variation through time in some aggregate measure of activity is not to be explained in the same way as one would explain variation in a single person's pattern of activity.

There is a parallel in this respect with object-oriented programming, as explained by Mitchel Resnick (1994). Imagine traffic flowing down a highway, with the drivers following the simple rule of driving as fast as possible until they reach some stipulated distance behind the preceding car, then keeping that distance. If one car suddenly slows down, a traffic jam forms as drivers reduce their speed. A time-lapse photograph of the traffic jam will show it moving backwards. Yet each car continues to move forward. It makes no sense to speak of the traffic jam as a gigantic car moving backwards. The jam is comprised of individual cars each moving forward, but interaction among those 
cars creates a higher level phenomenon that has different properties than that possessed by any of the individual cars. There is no gigantic car, and no individual car is moving backwards.

In the spirit of Weintraub (1993), Table 2 sets forth my version of a neoMengerian hard core. Since the neo-Mengerian framework is concerned with theorizing about the emergent properties of action over some duration of time while the neo-Walrasian framework seeks to give an account of eternally-valid observations, there is no good reason to expect a statement of their hard cores to have the same structure. Nonetheless, I have constructed this listing of a neo-Mengerian hard core to look the same as Weintraub's listing so as to facilitate comparison between the programs. This type of enforced comparability might not be the best way to articulate a neo-Mengerian research program because it applies a neo-Walrasian grammar to the neo-Mengerian program;

\section{Table 2: Hard Core of neo-Mengerian Research Program}

1 There exist both economic agents and social structure.

2 Agent preferences have both genetic and societal sources.

3 Agents choose ends as well as economize on means.

$4 \quad$ Choices are made in interrelated markets.

5 Agent knowledge is partial and is distributed among agents.

6 Observable outcomes are just one frame of a motion picture. 
nonetheless I can see pedagogical value in proceeding this way because of the familiarity of the neo-Walrasian grammar.

The only hard core element common to both programs is \#4, about the interrelated quality of markets: this element mirrors the common origin of the two parabolas $X^{2}$ and $-X^{2}$. The other five elements differ between the research programs, as befits their respective orientations toward temporality and eternity. Among those elements, differences in the first three are perhaps less significant than differences in the final two. Where element \#1 postulates only the existence of economic agents for the neo-Walrasian program, it also postulates the existence of social structure for the neo-Mengerian program. As Jason Potts (2000) explains, the neo-Walrasian program conceptualizes society as a field. In contrast, the neo-Mengerian program conceptualizes it as a network; the properties of a network, in contrast to those of a field, vary with its constitutive structure. Where element \#2 in the neo-Walrasian program postulates that agents operate with given preferences, its counterpart in the neo-Mengerian program postulates that some preferences arise through particular patterns of social relationships, while also recognizing that some preferences arise from genetic endowments. Element \#3 in the neo-Walrasian program postulates that agents act independently of one another in pursuing given ends; its counterpart in the neo-Mengerian program holds that agents choose ends as well as employ means, and with the choice of ends also entailing a societal component.

It is with the final two elements that the largest differences seem to appear. Element \#5 of the neo-Walrasian hard core holds that agents have all 
the necessary knowledge necessary to solve their optimization problems, whereas for the neo-Mengerian program knowledge is incomplete within any single agent and is distributed among agents. This element prevents any reduction of society to a representative agent, for the way that knowledge is used depends on the particular networked structure of society that is in place. Element \#6 of the neo-Walrasian program claims that observations are of coordinated equilibria, so that meaning can be derived from a snapshot. In contrast, the comparable element \#6 of the neo-Mengerian program claims that observations at some instant are but slices of some unfolding process, so that meaning is derived not from observation but from interpretation of actions and plans. This element embraces temporality to accommodate the internal generation of societal transformation, not as equilibrated responses to postulated exogenous shocks but as intelligible facets of economizing action.

With respect to Weintraub's two positive heuristics for the neo-Walrasian program, the neo-Mengerian program seems similar on the first heuristic and divergent on the second. Where the neo-Walrasian program theorizes in terms of agents optimizing over known options, the neo-Mengerian program theorizes about agents acting to implement plans that can be only incompletely articulated because the effect of any plan will depend on the future circumstances that will be influenced by future knowledge, which, in turn, will change through continuing human action as time passes. This alternative formulation is necessary to accommodate the internal generation of societal change. 
It is the second positive heuristic where the more significant difference would seem to appear between the two programs. The neo-Walrasian program holds that theoretical statements should refer to changes in equilibrium states. This follows from the sixth hard core proposition that all observations are of equilibrium states. Distinct observations refer to distinct equilibrium states, and this presumption advises use of the positive heuristic to make predictions about the effect of changes in exogenous variables on equilibrium states. In contrast, the neo-Mengerian program does not postulate that observations are of equilibrium states, but rather are blips on a screen whose pattern can be discerned only with the passing of time. Theories start from planning agents, as illustrated by the first positive heuristic, but the entire set of agents is never fully coordinated. To the contrary, plans continually are being revised or abandoned. Among other things, institutional arrangements arise to facilitate the revision and abandonment of plans (Lachmann 1971), and the neo-Mengerian counterpart to the second positive heuristic would counsel the construction of theories that, while consistent with agent planning, render intelligible the on-going generation of the institutional framework that governs human action and interaction (Mises 1957).

\section{Ontology, Epistemology, and Social-Economic Theory}

Both the neo-Walrasian and the neo-Mengerian programs theorize about generally orderly patterns of human activity. The objects of theorizing, however, differ between the programs, with one focusing on eternity and the other on 
temporality. Needless controversy and confusion can arise when there is incongruity between a program and the object of examination, as when a framework suitable to invariance across time and place is used to explore variability across time and place. Before exploring this point for two concrete economic situations, I shall I shall use a different setting to frame the priority of ontology over epistemology with respect to social theory. To be sure, a purely instrumentalist view of science would seem to elevate epistemology over ontology: the degree of congruity between a theory and its object, which is a matter of ontology, is irrelevant because what matters is the degree of congruity between theoretical prediction and observed experience, which is a matter of epistemology. ${ }^{5}$

Any analytical framework that distinguishes between universal principles and particular instances of those principles that can take on multiple guises is one that will involve both process and structure. Structure speaks to the universally recognizable features of the actions, both inventive and repetitive, that occur within society. It is possible simultaneously to embrace the recognition in Ecclesiastes that there is nothing new under the sun and the assertion of Heraclites that a person can't step twice into the same river. Both process and structure provide useful analytical orientation, but there is a question of which occupies the foreground. In a neo-Mengerian program, the foreground is occupied by process.

Consider two orderly social configurations, one is a parade and the other is a crowd of spectators leaving a stadium (to aid the comparison the parade 
should be large and take place on a wide boulevard). Further suppose that the two configurations are viewed from 5,000 feet, perhaps while standing in a hot-air balloon. Both would show long and wide movements of people in one direction, and with both configurations eventually breaking up and dissipating. Perhaps the main difference between the two configurations would be that the parade appears more orderly than the spectators. The parade would appear to be perfectly coordinated, or nearly so; the spectators would appear to be only imperfectly coordinated. The neo-Walrasian program must construe society as a parade, in which case the crowd would be construed as an imperfect parade. In principle it would be possible to develop some measure of the degree to which the crowd resembles the parade, and with this measure denoting a measure of imperfection when measured against the model of the perfectly coordinated parade.

What is present here is confusion between ontology and epistemology with respect to different social configurations. The parade is constituted as an organization; the spectators are constituted as an order. Each configuration can differ in the degree of coordination it exhibits. In some parades all participants might march in step and play in tune and on key, while other parades might display various degrees of cacophony. On some occasions the crowd of spectators might dissipate relatively quickly with everyone reaching their desired destinations pretty much as they had hoped, while other occasions might involve shoving, scuffles, and numerous cases of missed rides and late arrivals. 
A theorist who was asked to explain the variation in coordination among parades would surely take resort to such considerations as the musical and marching abilities of the members, the instructional talents of the conductor, and the amount of effort given to rehearsal. Such categories as these, however, are irrelevant to explaining the degree of coordination among spectators.

Explanation of this alternative type of coordination would involve such things as conventions, customs, and moral character. Epistemological questions can be addressed both to organizations and to orders, but the character of those questions depends on which type of object is being examined.

Both the parade and the crowd of spectators contain structure and can be described as an arrangement of nodes and connections among nodes. Those structures would be constituted differently, however, and those differences refer to processes by which those configurations are constituted. The parade is constituted through plans of a conductor or marshal. The crowd of spectators is constituted through each member's seeking to secure timely arrival at some destination while mostly conforming reasonably well to the similar actions of the other members of the crowd.

The neo-Mengerian program seeks to explore the on-going emergence of those social configurations that conform to the template offered by the image of crowds of spectators. In contrast, the Neo-Walrasian program holds that there are certain eternal features that pertain to all crowds. After all, at 5,000 feet crowds of spectators bear family resemblances to parades. Yet those crowds also vary across time and place, and the neo-Mengerian program seeks to give 
an account of the internal generation of such variability, even while recognizing that there is a surface-level resemblance between the two social configurations, as denoted by fourth element of the two hard cores held in common. For instance, it is impossible to work with a formulation wherein people generate and reform continually the world they experience and the same time work with a model of competitive equilibrium where everyone is a price taker. These alternative analytical windows are not so much antagonistic as they are noncommensurable. The existence of prices is a universal feature of social life, as are differences in prices among objects of trade. It is also true that there is immense variability in the objects of trade across time and place, as conveyed brilliantly by Georg Simmel's (1900) treatment of the changing sphere of alienability in property-governed relationships, the understanding of which requires employment of emergence-based concepts and categories. In the remainder of this paper I will offer two brief comparisons that highlight the noncommensurable character of the research programs, one of which is a standard topic from micro theory and the other from macro theory.

\section{Comparison \#1: Statics, Dynamics, and Market Theory}

Such concepts as preference, choice, and cost can be used to explain characteristic patterns of economic activity that are independent of time and place. Figure 1 presents a common illustration of this point, and at the same time can also be used to illustrate the non-commensurability of the neoWalrasian and the neo-Mengerian programs. Within a neo-Walrasian framework, 
Figure 1 illustrates the standard comparative statics of alternative equilibrium states in light of differences in given data. As compared with point $\alpha$ in the two panels, point $\beta$ pertains to a stronger preference to $X$ relative to $Y$. In Panel $A$ this appears as a stronger demand for X; in Panel B it appears as an alternative position on the production-possibility frontier. Figure 1 illustrates a response to a "what if" type of question. It answers that the structure of production would differ if preferences were those described by $\alpha$ than if they were those described by $\beta$. In other words, Figure 1 pertains to the timeless world of logic and asserts that different patterns of production will correspond to different patterns of preference.

To be sure, it is possible to use interpretative language to give the appearance of dynamic or historical relevance, as illustrated by Samuelson's (1947) use of a correspondence principle to connect statics and dynamics. For example, $\alpha$ and $\beta$ can be interpreted as corresponding to a change in preferences within a society over some interval of time. Alternative equilibrium allocations are interpreted as corresponding to differences or changes in postulated initial conditions. The object of theorization is the equilibrium allocation that is implied by the postulated initial conditions, with changes in those conditions being assimilated to exogenous shocks. Samuelson's notion of dynamics is purely notional and does not deal genuinely with action through time. In no way is the object of theorization the generation of a new social configuration out of a previous one. Questions of generation or transformation are simply outside the purview of the neo-Walrasian program, because these are 
phenomena that operate through time and so are not capable of being rendered intelligible by a framework that is invariant to time and place.

A focus on action through time must bring into the analytical foreground such phenomena as creativity, exploration, and learning. Such activities bring into play both the creation of new enterprises and revisions to the operation of old enterprises. They also bring changes in consumer valuations as people gain new insight into the relation between means and ends, as well as perhaps new insight into their ends. When time is allowed to pass, it is impossible for such points as $\alpha$ and $\beta$ in Figure 1 to refer to anything other than the logic of relationships outside of time. If time is allowed to pass, knowledge must be allowed to change, and once this happens the standard "given" conditions of comparative statics cannot be taken as given for genuine historical dynamics, as contrasted with the notional dynamics of comparative statics. It is no wonder that the passing of time has caused such consternation for economic theorists as to lead them to write such works as Economics and the Antagonism of Time (Vickers 1994) and Wrestling with Time (Currie and Steedman 1990). However antagonistic time might appear to theoretical efforts and no matter how much wrestling it might provoke, a neo-Mengerian research program is centrally concerned with phenomena that emerge through interaction over time among economizing individuals. To do this requires something like O'Driscoll and Rizzo's (1985) distinction between Newtonian Time and Real Time, recognizing that the correspondence principle is an exercise performed in Newtonian Time. 
Within the domain of Real Time, Figure 1 can serve a summarization of some stylized facts that pertain to distinct points in time. In this alternative, historical setting, the comparative output vectors $\left(X_{1}, Y_{1}\right)$ and $\left(X_{2}, Y_{2}\right)$ would be directly observable, and with the shift in preferences and demands denoted by $D_{1}$ $\rightarrow D_{2}$ being an interpretative hypothesis to help give an account of the historical observation. Where Figure 1 denotes sufficient information to give an account of the comparative statics, it is not sufficient to relate the historical dynamics by which the market configuration was transformed over the time period being considered. Comparative statics speaks to structure; historical dynamics speaks to process. The comparative statics of Figure 1 would assert that if all firms face identical U-shaped cost functions, the increased production of $\mathrm{X}$ would be provided wholly by new firms in the alternate equilibrium. This condition is necessitated by the logic of the problem setting. This logic of comparative statics does not, however, convey adequately the process by which $A \rightarrow B$. Most significantly, there is nothing corresponding to any announcement of an increase in demand for X. Such an announcement corresponds to a theoretical, what-if logic, but it does not correspond to any logic of practical action.

Absent some articulation of new demand conditions prior to any action to engage in production, production decisions are made by entrepreneurs who act on beliefs about future market opportunities within their field of vision and who act now to capture those opportunities when they arrive, if, indeed, they do arrive (Kirzner (1973)(1985)). Furthermore, there is no process of assignment that assures that just the right capacity will be added. Figure 1 might correspond to 
five additional firms producing $X$. But ten firms might seek to enter the market, in which case some entrepreneurial plans will fail and will be revised or even abandoned. Among other things, this means that conflicts will arise among firms, and also that social processes and procedures will emerge to settle such conflicts as those that arise through bankruptcy and insolvency (Wagner 2007). Within the neo-Mengerian orientation, the generation of such market formations would occupy the foreground of analytical attention. Those formations, moreover, are largely emergent products of interaction and not direct objects of choice-and most certainly are not taken as given data.

Stated differently, the neo-Walrasian program cannot accommodate a genuine theory of markets, as distinct from a theory of exchange. The principles of exchange are timeless, so the articulation of those principles fits nicely into the neo-Walrasian program. In contrast, markets are particular objects that evolve through time as people interact on the open-access commons created by the rules of property and contract. What is surely most notable about the buying and selling of used cars is not the presence of "lemons" (Akerlof 1970) but rather is the dramatic transformation in the character of the market for used cars over the past half-century. Cars of all kinds are far more reliable now. This greater reliability is a product of interaction among many people seeking to expand their custom, and expanding the extent of the market as a by-product of those efforts. A good part of this expansion entails the formation of new organizational arrangements and contractual forms. Advances in technology also contribute to 
market transformation, as illustrated by the development of diagnostic technology that contributes to the creation of new organizations and contractual forms.

In this history of market generation through time, there is an invariant search for gain among the participants. That search, however, involves interaction among those participants that leads to the emergence of market configurations that can be rendered intelligible ex post but could not have been created ex ante through choice, as one more implication of the impossibility of calculation without prices (Boettke 1998). To be sure, there is no guarantee that a historical period will be dominated by market expansion, for contraction is also possible. Expansion results from the efforts of people to capture what they sense to be unrealized profit opportunities; contraction results from the efforts of people to avoid being on the losing end of such efforts. In any case, there are multiple stories of market generation that can be examined within a neoMengerian program, each of which could conform ex post to the neo-Walrasian articulation conveyed by Figure 1 .

\section{Comparison \#2: Austrian-style Macro Theory}

Austrian cycle theory (ACT) has been nearly invisible within macrotheoretic discourse since the 1930s. This invisibility does not reflect empirical weakness but rather illustrates the non-commensurability of the neo-Mengerian and neo-Walrasian research programs. ACT is commonly expressed within a neo-Walrasian framework, with an initial equilibrium being disturbed by a credit expansion that drives the market rate of interest below the natural rate. What 
results is a two-stage form of comparative statics, wherein an initial boom in the capital-goods industries turns into a bust because consumers have not reduced their desire to buy consumer goods (Garrison 2001). Robert Lucas's (1975) model of the islands was actually a variation of ACT, and Lucas abandoned his support for this construction once he realized it did not fit within the neoWalrasian program that he embraced.

The problem with ACT is not that it is wrong but that it has been conveyed with intellectual vehicles that are not suited to the task (Wagner 1999). It is unfortunate in this respect that ACT has often been conveyed in comparative static fashion, for this treatment invited its assimilation to the neo-Walrasian program where it has no room to work. Comparative statics is independent of time. In contrast, any sequential analysis that is real and not merely notional must incorporate pertinent phenomena that are associated with the passing of time. ACT has always been conveyed in sequential fashion, but the neoWalrasian orientation reduces that sequence to something purely notional.

Figure 2 illustrates this point about ACT. Within a neo-Walrasian framework, the function $f(c)$ describes a pattern of declining marginal returns to capital projects or enterprises in light of the given initial conditions. Suppose current time preferences support the interest rate $r_{1}$ which in turn supports the capital structure denoted by $c_{1}$. The standard Austrian formulation distinguishes between two sources of a fall in the rate of interest to $r_{2}$ : a fall in time preference and an increase in bank credit without the increase in saving that accompanies the fall in time preference. The fall in time preference simply leads to a 
lengthening of the structure of production. The credit expansion starts the same way but then reverses direction because consumer preferences will not support the alternative structure of production. When this ACT analysis is conveyed within an equilibrium framework, it verges on incoherence. Suppose the capitalaxis in Figure 2 maps into the number of enterprises. The increase in bank credit is claimed to lead entrepreneurs denoted by $c_{2}-c_{1}$ to create new enterprises. Yet the given conditions for equilibrium support only $c_{1}$ enterprises. Thus those new enterprises are destined to fail because their value added is not worthwhile in light of prevailing time preferences. In the absence of monetary surprises and with no reason to postulate some alternative equilibrium configuration, the same $\mathrm{C}_{2}-\mathrm{c}_{1}$ firms that are born with be the ones that will die. Being rational and knowing their fate, those owners and investors will forsake such illusory prospects. The expansion will never happen because it violates the initial equilibrium conditions in conjunction with the presumption of full knowledge of those conditions and of the credit injection.

ACT can be rendered sensible only by working within a neo-Mengerian framework denoted by an evolving ecology of plans. A plan can be portrayed as a directed graph extending into the future from some point of origin. Figure 3 illustrates what I have in mind. The line designated "Actor's Plan" shows four nodes connected by intervals. This description in terms of nodes and intervals is intended to represent several relevant features concerning plans and their execution. One is that they extend from the present into the future. Hence, entrepreneurial action involves a projection from present onto future, as 
illustrated by Butos and Koppl (1993). Another feature is a distinction between plans and the execution of plans. Plans have a point of initial formulation, and can also be subject to amendment or revision. Amendment, however, is not something continuous. It is discrete. The first node in the actor's plan portrayed by Figure 3 denotes the initial formulation. The first interval denotes a period of subsequent execution in light of the original plan. The second node denotes a point of revision based on knowledge acquired since the initial formulation. The second interval denotes the enterprise's execution after revision, and with the third node denoting another point of revision.

Also denoted in Figure 3 is the insertion of substitute and complementary plans into the society's ecology of plans, and with these appearing at various times after the actor's plan has been created or revised (recall that the neoMengerian program works with motion pictures and not snapshots). Substitute plans are those that would reduce the value of the actor's plan while complementary plans would increase that value. There is no pre-coordination among plans. It is the insertion of other plans that leads possibly to revision of the original plan. It is also, of course, recognition of the possibility of such insertions that leads to flexibility, assessment, and revision being part of any plan. In the temporal sense depicted in Figure 3, the line segments between nodes constitute a type of short run where a plan is operated on a type of automatic pilot, so to speak, until judgments have been made to revise the plan. The long run in this conceptualization constitutes some planning horizon that provides navigational guidance, as represented by that final node in Figure 3 . 
A distinction between short run and long run is a staple distinction in economic analysis. At the micro level we distinguish between a short run where firms can vary their mix of inputs but not their scale of output and a long run where everything is variable. At the macro level, such a distinction finds expression in such notions as that a Phillips curve might exist in the short run due to monetary surprises but in the long run it can't exist because the one-time surprise will have become common knowledge. This distinction between short run and long run is a sensible feature of the neo-Walrasian program because it treats observations as equilibrated snapshots under different postulated conditions. Each such snapshot corresponds to sets of given data that are assumed to undergird the particular equilibrium snapshot that is being viewed.

In contrast, no such distinction is coherent at the societal level within the neo-Mengerian program, even though it is sensible at the individual level. The distinction between short run and long run has no referent when it is applied to society because there is no sentient creature who acts by creating and revising plans. At any date on a calendar, there will be some entrepreneurs who are initiating plans, there will be other entrepreneurs who are letting their plans operate, and there will be yet other entrepreneurs who are revising and even abandoning plans. At any particular moment we would expect the preponderance of enterprises to the operating somewhere along the execution interval of their plans. For instance, suppose that 95 percent of enterprises are operating within their execution phases, leaving five percent of enterprises at nodal positions where they are either creating or revising plans. This kind of 
situation would generate observations that would fit with the reasonably predictive properties of models of static equilibrium, as most enterprises would appear to be flying on automatic pilot. The hypothesis that observations pertained to a stationary state would pass an ordinary significance test, even though the process that generated that observation was one of emergent dynamics.

Those 95 percent of firms that at any instant are operating within their execution phases would appear to be acting consistently with a model of static equilibrium. The empirical success of static equilibrium modeling surely fits this situation. A scientific procedure that considers explanatory success in terms of averages, moreover, will be forced into making such a conclusion. To avoid such a conclusion, it is necessary to consider the entire population of enterprises and plans, and with especial attention given to outliers, and outliers of two forms. One form is the incipient enterprise that is just entering the enterprise ecology. The other form is the presence of creativity and plan revision within established enterprises, for we should never think that creativity comes only from new enterprises. The point is rather that in terms of a dichotomy between creative and routine, the preponderance of activity is routine and not creative. Indeed, the very notion of a plan as involving some duration of time between initiation and completion requires such preponderance. Furthermore, the observation that the world confronts us mostly as familiar from day to day is congruent with this preponderance as well. Yet there is surely a link between incipient creativity and static continuation, in that those static enterprises that do not respond to relevant 
developments within the nexus will lose standing and become candidates for death, whether through dissolution or takeover. What this suggests is that the appropriate grammar to apply to the nexus is the grammar that is appropriate to incipient enterprises (including the creative margins of established enterprises).

At any instant within the ecology of enterprises there are some firms that are on their death beds while there are other firms that are in the throes of birth. Credit injection, moreover, does not operate as some uniformly-spread liquid, but comes in lumps to particular enterprises (Horwitz 2000). Within this alternative frame of reference, a credit expansion may well facilitate some firms that prove to be successful, as well as exerting subsequent negative consequences. The overall impact, thus, cannot be captured only by some time series of aggregate measures, for those aggregates are composed of structural elements whose components are subject to variation.

The truly central feature of ACT is cousin to claims about the impossibility of collective planning. Idealize for a moment a catallaxy that is fully privately ordered. In standard equilibrium thinking, any aggregate measure of activity would show a flat line to indicate the steady state quality of the model. Catallaxy modeled in non-equilibrium fashion would not give any flat-line portrayal in the aggregate. Enterprises don't die instantly, to be replaced by new ones, again instantly. Not all plans mesh fully. Sometimes they collide, with debris scattered about. We speak of a construction industry, but a good chunk of that activity is devoted to remodeling and renovation, which in turn are activities that make sense only in the presence of failed plans that require reformation and revision. 
Some degree of variability is surely to be expected as a normal feature of a wellordered catallaxy—although it is not at all clear what kind of aggregate indicator could be used to express this idea, since the customary aggregates are sensible only in light of a presumption of equilibrium (similar to any comparison between parades and crowds of spectators).

In neo-Walrasian theorizing, much is made about the presumption that the mean forecast error is zero. This means that people are not systematically wrong, so that the claim of equilibrium appears to be sensible. Such an argument could be used to claim that it doesn't matter if particular entrepreneurs judge wrongly so long as the mean error is zero. This widespread claim is one more illustration of how a presumption of equilibrium neuters structure. The situation would be examined differently from within a neo-Mengerian framework because structure matters and does important work (or at least reflects important work). Most significantly, it means that a mean forecast error of zero means nothing. If there is any work to be done by such a statistic, it is to be done by the variance and not the mean, and it does so because the variance points to structure. An increase in error means an increased volume of particular lines of subsequently ill-fated commercial activity. These failed lines of activity have particular shape: people acquire special skills and fabricate particular tools and equipment. While these can always be redeployed, typically this will be only at some loss as compared with what would have been the case had the original plans worked out successfully. 


\section{A Concluding Observation}

One long-standing aphorism goes "the more things change the more they stay the same." There is much wisdom in this conjunction of Heraclites and Ecclesiastes. There are principles that govern the permanent things of social life, and the neo-Walrasian research program is suitable for illuminating some of those invariant features of social life, showing us again and again that no matter how much things change they do yet remain the same. And yet they do also change, and they change not because of exogenous shocks but because people continually generate change through interaction in their pursuit of plans. Plans reside in the world of intentional action, and intentional action is possible because the world is reasonably intelligible, perhaps reaching in the limit a neoWalrasian equilibrium. But this limit speaks to eternity and we are caught in temporality, and thereby are mutually engaged in a process of generating through interaction the world we are about to experience. The neo-Mengerian program is the research program that is suitable for addressing the spontaneously generated patterns of order that emerge through interaction among myriad intentionalities that inhabit the ecology of plans that constitutes a society.

Economic research has room for both types of research program, but it is also necessary that the phenomena studied be matched suitably to the appropriate research program; otherwise, weird claims can arise, as illustrated by suggestions that "lemons" will destroy the market for used cars when we know differently. The experience of obtaining lemons will do no such thing, and rather 
will elicit a stream of efforts to create such things as new organizational and contractual forms that will expand the extent of the market. It is the neoMengerian program that is the suitable framework for exploring the continual insertion of novelty into society, even though the future societal patterns that emerge can always be rendered intelligible in terms of the neo-Walrasian categories. 


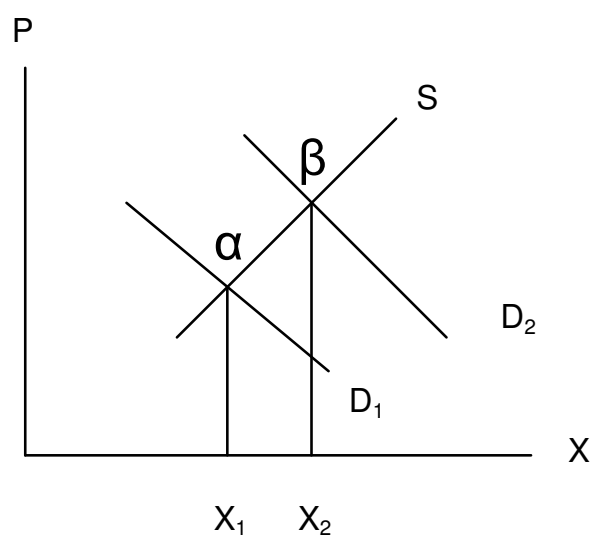

A: Single Market

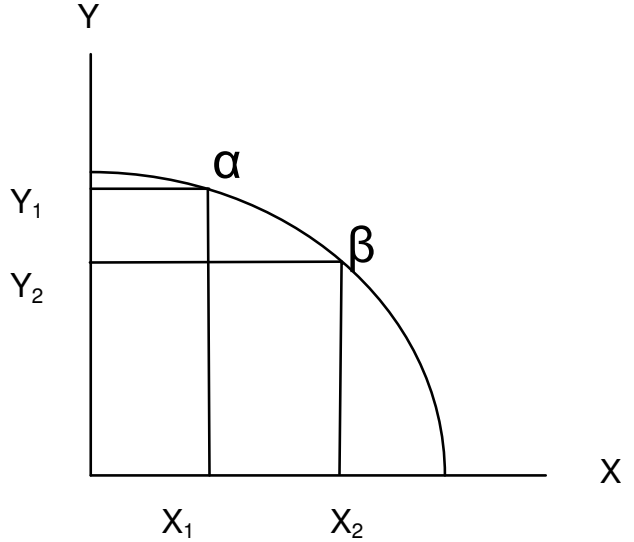

B: Multi-Market

Figure 1: Statics, Dynamics, and Market Theory 
Rate of return

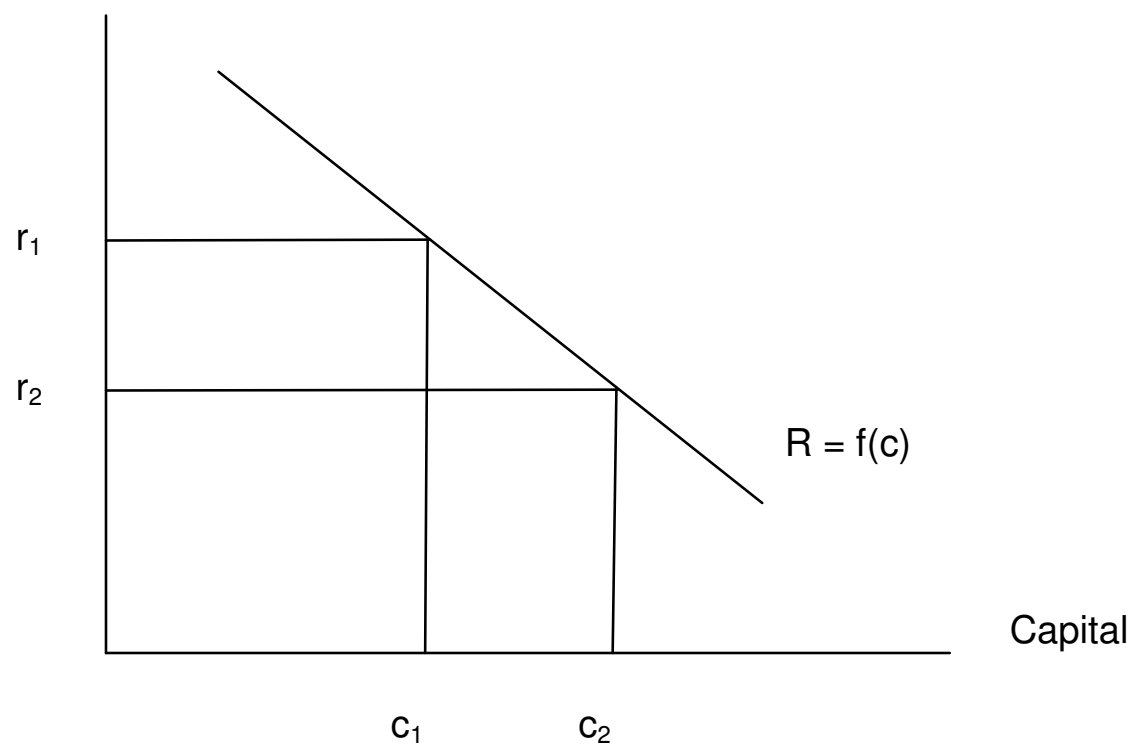

Figure 2: Credit Expansion and Structure of Production 


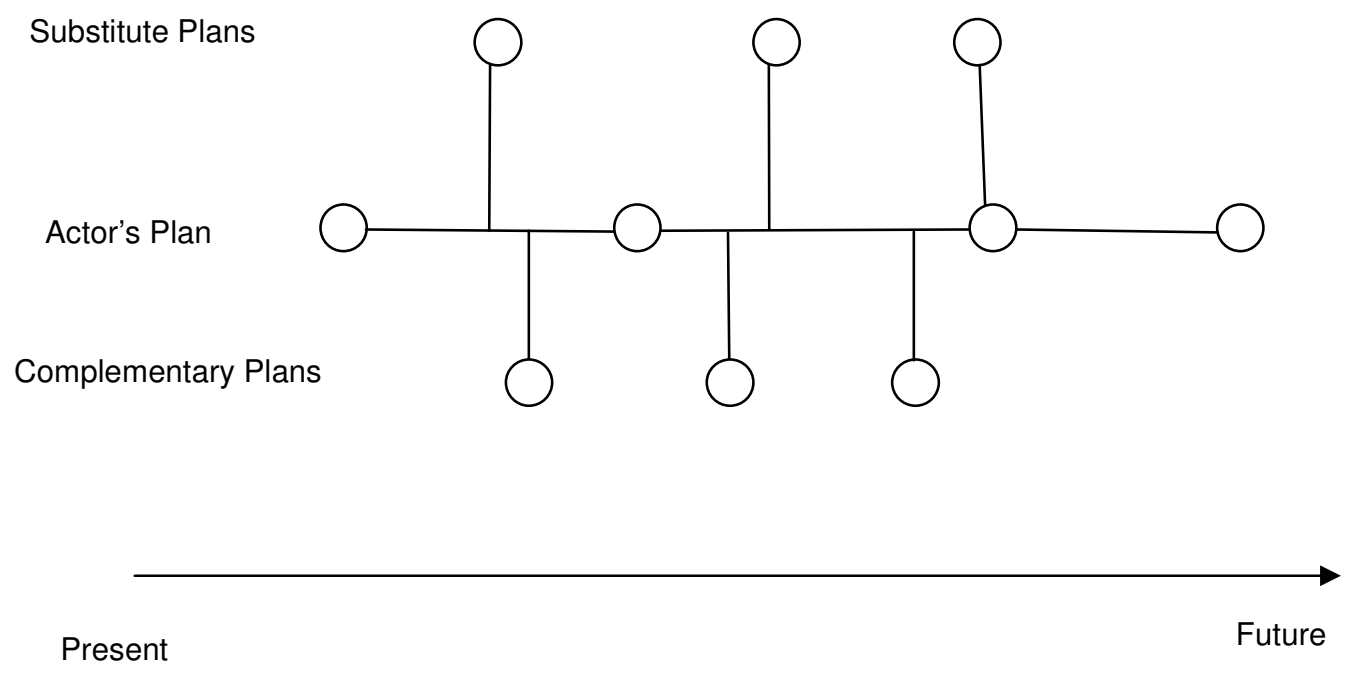

Figure 3: Entrepreneurial Plans as Directed Graphs 


\section{References}

Akerlof, G. 1970. "The Market for 'Lemons': Quality, Uncertainty, and the Market Mechanism." Quarterly Journal of Economics 84: 488-500.

Boettke, P. J. 1998. "Economic Calculation: The Austrian Contribution to Political Economy." Advances in Austrian Economics 5: 131-58.

Böhm, S. 1992. "Austrian Economics between the Wars: Some Historiographical Problems." In Austrian Economics: Tensions and New Directions, ed. by Bruce J. Caldwell and Stephan Böhm. Boston: Kluwer, pp. 1-30.

Boianovsky, M. and H-M Trautwein. 2007. "Johan Akerman vs. Ragnar Frisch on Quantitative Business Cycle Analysis." European Journal of the History of Economic Thought 14: 487-517.

Butos, W.N. and R. G. Koppl. 1993. "Hayekian Expectations: Theory and Empirical Applications." Constitutional Political Economy 4: 303-29.

Currie, M. and I. Steedman. 1990. Wrestling with Time. Ann Arbor: University of Michigan Press.

Daiches, D; P. Jones; and J. Jones. 1986. A Hotbed of Genius: The Scottish Enlightenment, 1730-1790. Edinburgh: Edinburgh University Press.

Epstein, J. M., ed. (2006). Generative Social Science: Studies in Agent-Based Computational Modeling. Princeton: Princeton University Press.

Friedman, M. 1953. "The Methodology of Positive Economics." In Idem, Essays in Positive Economics (Chicago: University of Chicago Press), pp. 3-46.

Garrison, R. W. 2001. Time and Money: The Macroeconomics of Capital Structure. London: Routledge.

Gloria-Palermo, S. 1999. The Evolution of Austrian Economics: From Menger to Lachmann. London: Routledge.

Horwitz, S. 2000. Microfoundations and Macroeconomics: An Austrian Perspective. London: Routledge.

Jaffé, W. 1965. Correspondence of Léon Walras and Related Papers. Amsterdam: North-Holland. 
Jaffé, W. 1976. "Menger, Jevons, and Walras De-Homogenized." Economic Inquiry 14: 511-24.

Kirzner, I. M. 1973. Competition and Entrepreneurship. Chicago: University of Chicago Press.

Kirzner, I. M. 1985. Discovery and the Capitalist Process. Chicago: University of Chicago Press.

Lachmann, L. 1971. The Legacy of Max Weber. Berkely, CA: Glendessary Press.

Lawson, T. 1997. Economics and Reality. London: Routledge.

Lawson, T. 2003. Reorienting Economics. London: Routledge.

Lewis, P., ed. 2004. Transforming Economics: Perspectives on the Critical Realist Project. London: Routledge.

Lindahl, E. 1919 [1939]. Studies in the Theory of Money and Credit. London: Allen \& Unwin.

Lucas, R. E., Jr. 1975. "An Equilibrium Moidel of the Business Cycle." Journal of Political Economy 83: 1113-44.

Menger, C. 1871 [1981]. Principles of Economics. New York: New York University Press.

Menger, C. 1883 [1985]. Investigations into the Method of the Social Sciences. New York: New York University Press.

Mises, L. 1957. Theory and History. New Haven, CT: Yale University Press.

Nigishi, T. 1985. Economic Theories in a non-Walrasian Tradition. Cambridge: Cambridge University Press.

O'Driscoll, G. P. and M. J. Rizzo. 1985. The Economics of Time and Ignorance. Oxford: Basil Blackwell.

Potts, J. 2000. The New Evolutionary Microeconomics: Complexity, Competence, and Adaptive Behaviour. Cheltenham, UK: Edward Elgar.

Reder, M. W. 1982. "Chicago Economics: Permanence and Change." Journal of Economic Literature 20: 1-38. 
Resnick, M. 1994. Turtles, Termites, and Traffic Jams: Explorations in Massively Parallel Microworlds. Cambridge: MIT Press.

Rosen, S. 1997. "Austrian and Neoclassical Economics: Any Gains from Trade?" Journal of Economic Perspectives 11: 139-52.

Simmel, G. 1900 [1978]. The Philosophy of Money. London: Routledge.

Vickers, D. 1994. Economics and the Antagonism of Time. Ann Arbor: University of Michigan Press.

Viner, J. 1972. The Role of Providence in the Social Order. Princeton, NJ: Princeton University Press.

Vriend, N. J. (2002). "Was Hayek an Ace?" Southern Economic Journal 68: 811-840.

Wagner, R. E. 1999. "Austrian Cycle Theory: Saving the Wheat while Discarding the Chaff." Review of Austrian Economics 12: 65-80.

Wagner, R. E. 2007. Fiscal Sociology and the Theory of Public Finance. Cheltenham, UK: Edward Elgar.

Walras, L. (1874 [1954]) Elements of Pure Economics. Homewood, IL: Richard D. Irwin.

Weintraub, E. R. 1993. General Equilibrium Analysis: Studies in Appraisal. Ann Arbor: University of Michigan Press.

Yeager, L. B. 1997. "Austrian Economics, Neoclassicism, and the Market Test." Journal of Economic Perspectives 11: 153-65. 


\section{Endnotes}

${ }^{1}$ I am grateful to several of the participants at the Wirth Institute conference for helpful comments and insights, and especially Roger Koppl and Stephan Böhm, as well as an anonymous referee, for post-conference suggestions.

${ }^{2}$ This quotation appears in Sandye Gloria-Palermo (1999, p. 20), and was taken from the correspondence of Walras collected in Jaffé (1965). Further discussion on the divergence between Menger and Walras is presented in Jaffé (1976). See, also, Negishi (1985), who explains that the differences between Menger and Walras far exceed the similarities.

${ }^{3}$ This dichotomy was also at work in fueling the debate between Johan Akerman and Ragnar Frish over business cycles, with Akerman thinking in terms of process and Frish in terms of equilibrium states, as explained by Boianovsky and Trautwein (2007).

${ }^{4}$ For a lucid statement of the principle that models in the social sciences should aim to generate their relationships and not just postulate them, see the essays in Epstein, ed. (2006). Similarly, Erik Lindahl's (1919 [1939]) articulation of the distinction between micro and macro likewise reflects a neo-Mengerian orientation, in contrast to the neo-Walrasian orientation of the orthodox distinction between micro and macro. For Lindahl, micro theory pertained to individual action, the domain of praxeology; macro theory pertained to interaction among people, the domain of catallaxy, and with that domain incorporating the various institutional arrangements that are generated through interaction.

${ }^{5}$ The primacy of the epistemological in economic discourse is given its classic statement in Friedman (1953). For recognition of the primacy of ontological presumptions, see Lawson (1997)(2003) and Lewis (2004). 